\title{
ACTIVITY AND CONSCIOUSNESS ${ }^{1}$
}

\author{
Aleksei Nikolaevich Leontiev ${ }^{2}$
}

In examining this problem the first point we have to consider is the question of the significance of the category of activity in any interpretation of how human consciousness is determined.

There are two approaches to this major question. One of them postulates the direct dependence of the phenomena of consciousness on the various influences exerted upon man's receptive systems. This approach was expressed with classical clarity in the 19th-centurypsycho-physics and physiology of the sense organs. The main task of research in those days was to establish the quantitative dependence of sensations, regarded as elements of consciousness, on the physical parameters of the stimuli affecting the sense organs. These researches were thus based on the "stimulus-response" pattern.

The limitations of this approach lay in the fact that it assumed, on the one hand, things and objects and, on the other, a passive subject influenced by them. In other words, this approach ignores the significant element of the actual relations of the subject with the objective world; it ignores his activity. Such abstraction is, of course, admissible, but only within the bounds of an experiment intended to discover certain properties of elementary structures and functions contributing to the realisation of certain mental processes. The moment one goes beyond these narrow limits, however, one realises the inadequacy of this approach, and it was this that compelled the early psychologists to explain psychological facts on the basis of special forces, such as that

\footnotetext{
${ }^{1}$ Published in Russian in the journal Voprosyfilosofii, n. 12, p. 129-140 (1972) and English in the book Philosophy in the USSR, Problems of Dialectical Materialism (Moscow, 1977, p. 180-202). Available at Marxists Internet Archive [http://www.marxists.org/]. Reproduction Rights: (cc)) BY-s/ licensed under a Creative Commons License.

2 A.N. Leontiev worked with Lev Vygotsky (1896-1934) and Alexander Luria (1902-1977) from 1924 to 1930, collaborating on the development of a Marxist psychology as a response to behaviorism and the focus on the stimulus-response mechanism as explanation for human behavior. Later, he became the Head of the Psychology Department at the Faculty of Philosophy of Moscow State University. In 1966, Leontiev became the first ever Dean of the newly established Faculty of Psychology at the Moscow State University, where he worked until his death in 1979.
} 
of active apperception, inner intention or will, etc., that is to say, to appeal to the active nature of the subject, but only in an idealistically interpreted, mystified form.

There have been many attempts to overcome the theoretical difficulties created by the postulate of immediacy underlying the approach we have just mentioned. For example, it is stressed that the effects of external influences are determined not immediately by the influences themselves, but depend on their refraction by the subject. In other words, attention is concentrated on the fact that external causes act through the medium of internal conditions. But this notion can be interpreted in various ways, depending on what is meant by internal conditions. If they are taken to mean a change in the internal states of the subject, the notion offers us nothing essentially new. Any object can change its states and hence manifest itself in different ways in its interaction with other objects. Footprints show on soft ground but not on hard; a hungry animal reacts to food differently from one that is well fed; the literate person's reaction to a letter is different from that of the illiterate. It is another matter if by "internal conditions" we mean the special features of processes that are active in the subject. But then the main question is what these processes are that mediate the influences of the objective world reflected in the human brain.

The basic answer to this question lies in acknowledging that these processes are those that realise a person's actual life in the objective world by which he is surrounded, his social being in all the richness and variety of its forms. In other words, these processes are his activity.

This proposition requires the further definition that by activity we mean not the dynamics of the nervous, physiological processes that realise this activity. A distinction must be drawn between the dynamics and structure of mental processes and the language that describes them, on the one hand, and the dynamics and structure of the subject's activity and the language describing them, on the other.

Thus in dealing with the problem of how consciousness is determined we are confronted with the following alternative, either to accept the view implied in the "axiom of immediacy", i.e., proceed from the "object-subject" pattern (or the "stimulusresponse" pattern, which is the same thing), or to proceed from a pattern which includes a third, connecting link - the activity of the subject (and, correspondingly, its means and mode of appearance), a link which mediates their interconnections, that is to say, to proceed from the "subject-activity-object" pattern.

\begin{tabular}{|c|c|c|c|c|}
\hline Qenista Dialectus & Ano 2 & n. 4 & Janeiro-Junho 2014 & p. $159-183$ \\
\hline
\end{tabular}


In the most general form this alternative may be presented as follows. Either we take the stand that consciousness is directly determined by surrounding things and phenomena, or we postulate that consciousness is determined by being, which, in the words of Marx, is nothing else but the process of the actual life of people.

But what is the actual or real life of people?

Being, the life of each individual is made up of the sum-total or, to be more exact, a system, a hierarchy of successive activities. It is in activity that the transition or "translation" of the reflected object into the subjective image, into the ideal, takes place; at the same time it is also in activity that the transition is achieved from the ideal into activity's objective results, its products, into the material. Regarded from this angle, activity is a process of intertraffic between opposite poles, subject and object.

Activity is a non-additive unit of the corporeal, material life of the material subject. In the narrower sense, i.e., on the psychological plane, it is a unit of life, mediated by mental reflection, by an image, whose real function is to orientate the subject in the objective world.

However, no matter what the conditions and forms in which man's activity proceeds, no matter what structure it acquires, it cannot be regarded as something extracted from social relations, from the life of society. Despite all its diversity, all its special features the activity of the human individual is a system that obeys the system of relations of society. Outside these relations human activity does not exist. How it exists is determined by the forms and means of material and spiritual communication that are generated by the development of production and that cannot be realised except in the activity of specific individuals. It stands to reason that the activity of every individual depends on his place in society, on his conditions of life.

This has to be mentioned because of the persistent efforts of the positivists to oppose the individual to society. Their view is that society provides only an external environment to which man has to adapt himself in order to survive, just as the animal must adapt itself to its natural environment. Man's activity is shaped by the success or failure of this adaptation even though this may be indirect (for example, through the attitude taken to it by the reference group). But the main thing is ignored, that in society man finds not only his external conditions to which he must adapt his activity, but also that these very social conditions carry in themselves the motives and aims of his activity, the ways and means of its realisation; in a word, that society produces human activity. This is not to say, of course, that the activity of the individual merely copies

\begin{tabular}{|l|l|l|l|l|}
\hline Qepista Dialectus & Ano 2 & n. 4 & Janeiro-Junho 2014 & p. 159-183 \\
\hline
\end{tabular}


and personifies the relationships of society and its culture. There are some very complex cross-links which rule out any strict reduction of one to the other.

The basic, constituent feature of activity is that it has an object. In fact, the very concept of activity (doing, Tätigkeit) implies the concept of the object of activity. The expression "objectless activity" has no meaning at all. Activity may appear to be objectless, but the scientific investigation of activity necessarily demands the discovery of its object. Moreover, the object of activity appears in two forms: first, in its independent existence, commanding the activity of the subject, and second, as the mental image of the object, as the product of the subject's "detection" of its properties, which is effected by the activity of the subject and cannot be effected otherwise.

The circular nature of the processes effecting the interaction of the organism with the environment has been generally acknowledged. But the main thing is not this circular structure as such, but the fact that the mental reflection of the objective world is not directly generated by the external influences themselves, but by the processes through which the subject comes into practical contact with the objective world, and which therefore necessarily obey its independent properties, connections, and relations. This means that the afferent agent, which controls the processes of activity, is primarily the object itself and only secondarily its image as the subjective product of activity, which registers, stabilises and carries in itself the objective content of activity.

The genetically initial and fundamental form of human activity is external activity, practical activity. This proposition has important implications, particularly as psychology, traditionally, has always studied the activity of thought and the imagination, acts of memory, and so on, since only such internal activity was considered psychological. Psychology therefore ignored the study of practical, sensual activity. And even if external activity figured to some extent in the traditional psychology, it did so only as an expression of internal activity, the activity of the consciousness.

What exactly do we have in mind when we speak of activity? Let us consider the simplest process, the process of perceiving the resilience of an object. This is an afferent or external-motor process, which may aim at performing a practical task, for example, the deformation of the object. The image that arises in the course of this process is, of course, a mental image and is therefore undoubtedly qualified for psychological study. But in order to understand the nature of this image I must study the process that generates it, and in the given case this is an external and practical process. Like it or not,

\begin{tabular}{|c|c|c|c|c|}
\hline Qenista Dialectus & Ano 2 & n. 4 & Janeiro-Junho 2014 & p. $159-183$ \\
\hline
\end{tabular}


I am compelled to include this process as part of the object of my psychological investigation.

Of course, the mere establishing of the need for psychological investigation to extend to the sphere of external objective activity does not solve the problem because it may be assumed that, although external objective activity comes within the range of psychological investigation, such activity plays a secondary role, since it is guided by the internal psychological process that lies beyond it, and that for this reason psychological investigation in fact does not provide for the investigation of this activity.

This is a point to be reckoned with, but only if one assumes that external activity is one-sidedly dependent on the image which controls it, and which may or may not be reinforced by the result of this activity. But this is not so. Activity is bound to encounter man-resisting objects that divert, change and enrich it. In other words, it is external activity that unlocks the circle of internal mental processes, that opens it up to the objective world.

It will readily be appreciated that the reality with which the psychologist is concerned is essentially richer and more complex than the bare outline of the way the image arises from contact with the object that we have just drawn. But no matter how far removed the psychological reality may be from this crude pattern, no matter how profound the metamorphoses of activity may be, activity will under all circumstances remain the materialiser of the life of any given individual.

The old psychology was concerned only with internal processes, with the activity of the consciousness. Moreover, for a long time it ignored the question of the origin of these activities, i.e., their actual nature. Today the proposition that internal processes of thought are produced from the external has become almost generally acknowledged. At first, for example, internal mental processes take the form of external processes involving external objects and, as they become internal processes, these external processes do not simply change their form but undergo a certain transformation, becoming more general, contracted, and so on. All this is quite true, of course, but it must be stressed that internal activity is genuine activity, which retains the general structure of human activity, no matter in what form it takes place. Once we acknowledge the common structure of external, practical activity and internal, mental activity we can understand the exchange of elements that constantly takes place between them, we can understand that certain mental actions may become part of the structure of direct practical, material activity and, conversely, external-motor operations

\begin{tabular}{|l|l|l|l|l|}
\hline Qevista 2 ialectus & Ano 2 & n. 4 & Janeiro-Junho 2014 & p. 159-183 \\
\hline
\end{tabular}


may serve the performance of mental action in the structure of purely cognitive activity. In the present age, when the integration and interpenetration of these forms of human activity is taking place before our eyes, when the historic opposition between them is being steadily and increasingly erased, the significance of the proposition is selfevident.

Up to now we have been talking about activity in the general, collective meaning of this concept. In reality, however, we have to deal with concrete, specific activities, each of which satisfies a definite need of the subject, is oriented towards the object of this need, disappears as a result of its satisfaction and is reproduced perhaps in different conditions and in relation to a changed object.

The main thing that distinguishes one activity from another lies in the difference between their objects. It is the object of activity that endows it with a certain orientation. In the terminology I have been using the object of activity is its motive. Naturally, this may be both material and ideal; it may be given in perception or it may exist only in imagination, in the mind.

So, different activities are distinguished by their motives. The concept of activity is necessarily bound up with the concept of motive. There is no such thing as activity without a motive; "unmotivated" activity is not activity that has no motive, but activity with a subjectively and objectively hidden motive.

The basic "components" of separate human activities are the actions that realise them. We regard action as the process that corresponds to the notion of the result which must be achieved, that is, the process which obeys a conscious goal. Just as the concept of motive is correlative with the concept of activity, so the concept of goal is correlative with that of action.

Historically, the appearance in activity of goal-oriented action processes was the result of the emergence of a society based on labour. The activity of people working together is stimulated by its product, which at first directly corresponds to the needs of all participants. But the simplest technical division of labour that arises in this process necessarily leads to the emergence of intermediate, partial results, which are achieved by individual participation in the collective labour activity, but which in themselves cannot satisfy the need of each participant. This need is satisfied not by the "intermediate" results, but by the share of the product of the total activity that each receives thanks to the relationships between the participants arising in the process of labour, that is, the social relations.

\begin{tabular}{|c|c|c|c|c|}
\hline Qenista Dialectus & Ano 2 & n. 4 & Janeiro-Junho 2014 & p. $159-183$ \\
\hline
\end{tabular}


It will easily be understood that this "intermediate" result which forms the pattern of man's labour processes must be identified by him subjectively as well, in the form of an idea. This is, in effect, the setting of the goal, which determines the method and character of the individual's activity.

The identification of these goals and the formation of activities designed to achieve them lead to a kind of splitting up of functions that were previously united in their motive. Let us assume that a person's activity is stimulated by food, this is its motive. However, in order to satisfy the need for food he must perform actions that are not directly aimed at obtaining food. For example, one of his goals may be the making of trapping gear. Whether he himself will later use the gear he makes or pass it on to other participants in the hunt and receive part of the common catch or kill, in either case his motive and goal do not directly coincide, except in particular cases.

The separation of goal-oriented actions as components of human activity naturally brings up the question of their internal relations. As we have already said, activity is not an additive process. Hence actions are not separate things that are included in activity. Human activity exists as action or a chain of actions. If we were to mentally subtract from activity the actions which realise it there would be nothing left of activity. This can be expressed in another way. When we consider the unfolding of a specific process - external or internal - from the angle of the motive, it appears as human activity, but when considered as a goal-oriented process, it appears as an action or a system, a chain of actions.

At the same time activity and action are both genuine and, moreover, noncoincidental realities, because one and the same action may realise various activities, may pass from one activity to another, thus revealing its relative independence. This is due to the fact that the given action may have quite different motives, i.e., it may realise completely different activities. And one and the same motive may generate various goals and hence various actions.

So, in the general flow of activity which forms human life in its highest manifestations (those that are mediated by mental reflection), analysis first identifies separate activities, according to the criterion of the difference in their motives. Then the action processes obeying conscious goals are identified, and finally, the operations that immediately depend on the conditions for the attainment of a specific goal.

These "units" of human activity form its macrostructure. The analysis by which they are identified is not a process of dismembering living activity into separate

\begin{tabular}{|l|l|l|l|l|}
\hline Qepista Dialectus & Ano 2 & n. 4 & Janeiro-Junho 2014 & p. 159-183 \\
\hline
\end{tabular}


elements, but of revealing the relations which characterise that activity. Such systems analysis simultaneously rules out any possibility of a bifurcation of the reality that is being studied, since it deals not with different processes but rather with different planes of abstraction. Hence it may be impossible at first sight, for example, to judge whether we are dealing, in a given case, with action or with operation. Besides, activity is a highly dynamic system, which is characterised by constantly occurring transformations. Activity may lose the motive that evoked it, in which case it turns into an action that realises perhaps a quite different relationship to the world, a different activity; conversely, action may acquire an independent motivating force and become a special kind of activity; and finally, action may be transformed into a means of achieving a goal capable of realising different actions.

The indisputable fact remains that man's activity is regulated by mental images of reality. Anything in the objective world that presents itself to man as the motives, goals and conditions of his activity must in some way or another be perceived, understood, retained and reproduced by his memory; this also applies to the processes of his activity, and to himself, his states and individual features.

Hence it follows that man's consciousness in its immediacy is the picture of the world that unfolds itself to him, a picture in which he himself, his actions and states, are included.

For the uninitiated person the existence of this subjective picture will not, of course, give rise to any theoretical problems; he is confronted with the world, not the world and a picture of the world. This spontaneous realism contains a real, if naive, element of truth. It is a different matter when we equate mental reflection with consciousness; this is no more than an illusion of our introspection. This illusion arises from the seemingly unlimited range of consciousness. When we ask ourselves if we are aware of this or that phenomenon, we set ourselves the task of becoming aware of it and, of course, in practice we instantly accomplish this task. It was necessary to devise a special technique of using the tachistoscope in order to experimentally separate the field of perception from the field of consciousness.

On the other hand, certain well-known facts that can easily be reproduced in laboratory conditions tell us that man is capable of complex adaptive processes in relation to objects of the environment without being at all conscious of their images; he negotiates obstacles and even manipulates things without "seeing" them at all.

\begin{tabular}{|c|c|c|c|c|}
\hline Qenista Dialectus & Ano 2 & n. 4 & Janeiro-Junho 2014 & p. $159-183$ \\
\hline
\end{tabular}


It is a different matter if he must make or change a thing according to a pattern or represent, portray some objective content. When I shape, let us say, a pentagon out of wire, or draw it, I must necessarily compare the notion I have of it with the objective conditions, with the stages of its realisation in the product; I must internally measure one against the other. Such measurings or fittings demand that my notion should for me appear to be, as it were, on the same plane as the objective world and yet not merging with it. This is particularly evident in cases when we are dealing with problems that have to be solved by preliminarily performing "in our heads" the mutual spatial displacement of the images of objects that have to be correlated. Such, for example, is the kind of problem that demands the mental turning round of a figure inscribed in another figure.

Historically the need for such a "presentation" of the mental image to the subject arises only during the transition from the adaptive activity of animals to the productive, labour activity that is peculiar to man. The product to which activity is now directed does not yet actually exist. So it can regulate activity only if it is presented to the subject in such a form that enables him to compare it with the original material (object of labour) and with its intermediate transformations. What is more, the mental image of the product as a goal must exist for the subject in such a way that he can act with this image - modify it according to the conditions at hand. Such images are conscious images, conscious notions or, in other words, the phenomena of consciousness.

In itself the need for phenomena of consciousness to arise in a man's head tells us nothing about the process by which they arise. It does, however, give us a clear target for our study of this process. The point is that in terms of the traditional diadic "objectsubject" pattern the existence of consciousness in the subject is accepted without any explanations, unless we count the interpretations that assume the existence in our heads of some kind of observer contemplating the pictures woven by cerebral processes.

The method of scientific analysis of the generation and functioning of human consciousness - social and individual - was discovered by Marx. The result was that the study of consciousness shifted its target from the subjectivity of the individual to the social systems of activity.

It is self-evident that the explanation of the nature of consciousness lies in the peculiar features of human activity that create the need for it - in activity's objective, productive character. Labour activity is imprinted, perpetuated in its product. There takes place, in the words of Marx, a transition of activity into a static property. This

\begin{tabular}{|c|c|c|c|c|}
\hline Qevista Dialectus & Ano 2 & n. 4 & Janeiro-Junho 2014 & p. $159-183$ \\
\hline
\end{tabular}


transition is the process of the material embodiment of the objective content of activity, which now presents itself to the subject, that is to say, arises before him in the form of an image of the object perceived.

In other words, a rough approximation of the generation of consciousness may be outlined thus: the representation controlling activity, when embodied in an object, acquires its second, "objectivised" existence, which can be sensuously perceived; as a result the subject, as it were, sees his own representation in the external world. When it has thus been duplicated, it is consciously understood. This pattern is not valid, however. It takes us back to the previous subjectively-empirical, essentially idealistic point of view which stresses above all the fact that this particular transition is predicated on consciousness, on the subject's having certain representations, intentions, mental plans, patterns or "models", that is to say, mental phenomena objectivised in activity and its products. As for the subject's activity itself, it is controlled by consciousness and performs in relation to its contents only a transfer function and the function of their "reinforcement or non-reinforcement".

But the main thing is not to indicate the active, controlling role of consciousness. The main problem lies in understanding consciousness as a subjective product, as a manifestation in different form of the essentially social relations that are materialised by man's activity in the objective world. Activity is by no means simply the expresser and vehicle of the mental image objectivised in its product. The product records, perpetuates not the image but the activity, the objective content which it objectively carries within itself.

The subject-activity-object transitions form a kind of circular movement, so it may seem unimportant which of its elements or moments is taken as the initial one. But this is by no means movement in a closed circle. The circle opens, and opens specifically in sensuous practical activity itself. Entering into direct contact with objective reality and submitting to it, activity is modified and enriched; and it is in this enriched form that it is crystallised in the product. Materialised activity is richer, truer than the consciousness that anticipates it. Moreover, for the consciousness of the subject the contributions made by his activity remain hidden. So it comes about that consciousness may appear to be the basis of activity.

Let us put this in a different way. The reflection of the products of the objective activity which materialises the connections and relationships between social individuals appears to them to be phenomena of their consciousness. But in reality there lie beyond

\begin{tabular}{|l|l|l|l|l|}
\hline Qepista Dialectus & Ano 2 & n. 4 & Janeiro-Junho 2014 & p. 159-183 \\
\hline
\end{tabular}


these phenomena the above-mentioned objective connections and relationships, not in a clear and obvious form but in a sublated form hidden from the subject. At the same time the phenomena of consciousness constitute a real element in the motion of activity. This is what makes them essential,that is to say, the conscious image performs the function of ideal measure, which is materialised in activity.

This approach to consciousness makes a radical difference to the way in which the problem of the correlation of the subjective image and the external object is posed. It gets rid of the mystification of this problem, which the postulate of immediacy creates. If one proceeds from the assumption that external influences immediately, directly evoke in us, in our brain, a subjective image, one is straightaway faced with the question as to how it comes about that this image appears to exist outside us, outside our subjectivity, in the coordinates of the external world.

In terms of the postulate of immediacy this question can be answered only by assuming a process of secondary, so to speak, projection of the mental image into the external world. The theoretical weakness of such an assumption is obvious. Besides it is clearly in contradiction with the facts, which testify that the mental image is from the very beginning "related" to a reality that is external to the subject's brain, and that it is not projected into the external world but rather extracted, scooped out of it. Of course, when I speak of "scooping out", this is no more than a metaphor. It does, however, express a real process that can be scientifically researched, the process of the subject's assimilation of the objective world in its ideal form, the form of its conscious reflection.

This process originally arises in the system of objective relations in which the transition of the objective content of activity into its product takes place. But for this process to be realised it is not enough that the product of activity, having absorbed this activity, should present itself to the subject as its material properties; a transformation must take place that allows it to emerge as something of which the subject is aware, that is to say, in an ideal form. This transformation is effected by means of language, which is the product and means of communication of people taking part in production. Language carries in its meanings (concepts) a certain objective content, but a content completely liberated from its materiality.

Thus, individual consciousness as a specifically human form of the subjective reflection of objective reality may be understood only as the product of those relations and mediacies that arise in the course of the establishment and development of society. Outside the system of these relations (and outside social consciousness) the existence of

\begin{tabular}{|c|c|c|c|c|}
\hline Qenista Dialectus & Ano 2 & n. 4 & Janeiro-Junho 2014 & p. $159-183$ \\
\hline
\end{tabular}


individual mentality, a psyche, in the form of consciousness is impossible, especially as even the study of the phenomena of consciousness in terms of human activity allows us to understand them only on the condition that man's activity itself is regarded as a process included in the system of relations, a process that realises his social being, which is the means of his existence also as a natural, corporeal creature.

Of course, the above-mentioned conditions and relations which generate human consciousnesscharacterise it only at the earliest stages. Subsequently, as material production and communication develop, people's consciousness is liberated from direct connection with their immediate practical labour activity both by the isolation and subsequent separation of intellectual production and the instrumentalisation of language. The range of what has been created constantly widens, so that man's consciousness becomes the universal, though not the only, form of mental reflection. In the course of this process it undergoes certain radical changes.

To begin with, consciousness exists only in the form of a mental image revealing the surrounding world to the subject. Activity, on the other hand, still remains practical, external. At a later stage activity also becomes an object of consciousness; man becomes aware of the actions of other men and, through them, of his own actions. They are now communicable by gestures or oral speech. This is the precondition for the generation of internal actions and operations that take place in the mind, on the "plane of consciousness". Image-consciousness becomes also activity-consciousness. It is in this fullness that consciousness begins to seem emancipated from external, practical sensuous activity and, what is more, appears to control it.

Another fundamental change that consciousness undergoes in the course of historical development consists in the destruction of the original cohesion of the consciousness of the labour collective and that of its individual members. This occurs because the range of consciousness widens, taking in phenomena that belong to a sphere of individual relations constituting something special in the life of each one of them. Moreover, the class division of society puts people into unequal, opposed relations to the means of production and the social product; hence their consciousness experiences the influence of this inequality, this opposition. At the same time ideological notions are evolved and enter into the process by which specific individuals become aware of their real life relations.

There thus arises a complex picture of internal connections, interweaving and intertraffic generated by the development of internal contradictions, which in abstract

\begin{tabular}{|c|c|c|c|c|}
\hline Qenista Dialectus & Ano 2 & n. 4 & Janeiro-Junho 2014 & p. $159-183$ \\
\hline
\end{tabular}


form become apparent in the analysis of the simplest relations characterising the system of human activity. At first glance the immersion of research in this intricate picture may appear to divert it from the task of specific psychological study of the consciousness, and lead to the substitution of sociology for psychology. But this is not the case at all. On the contrary, the psychological features of the individual consciousness can only be understood through their connections with the social relations in which the individual becomes involved.

In the phenomena of consciousness we discover, above all, their sensuous fabric. It is this fabric that forms the sensuous composition of the specific image of reality actually perceived or arising in the memory, referred to the future or perhaps only imagined. These images may be distinguished by their modality, their sensuous tone, degree of clarity, greater or less persistence, and so on.

The special function of the sensuous images of consciousness is that they add reality to the conscious picture of the world revealed to the subject. In other words, it is thanks to the sensuous content of consciousness that the world is seen by the subject as existing not in his consciousness but outside his consciousness, as the objective "field" and object of his activity. This assertion may appear paradoxical because the study of sensuous phenomena has from time immemorial proceeded from positions that lead, on the contrary, to the idea of their "pure subjectivity", their "hieroglyphic nature". Accordingly, the sensuous content of images was not seen as something effecting "the immediate connection between consciousness and the external world", but rather as a barrier between them.

In the post-Helmholtz period the experimental study of the processes of perception achieved striking successes. The psychology of perception is now inundated with facts and individual hypotheses. But the amazing thing is that, despite these successes, Helmholtz's theoretical position has remained unshaken. Admittedly, in most psychological studies it is present invisibly, backstage, so to speak. Only a few psychologists discuss it seriously and openly, like Richard L. Gregory, for example, the author of what is probably the most absorbing of modern books on visual perception ${ }^{3}$.

The strength of Helmholtz's position lies in the fact that, in studying the physiology of eyesight, he understood the impossibility of inferring the images of objects directly from sensations, of identifying them with the patterns drawn by light

${ }^{3}$ R. L. Gregory, The Intelligent Eye, London 1970.

\begin{tabular}{|l|l|l|l|l|}
\hline Qevista 2 ialectus & Ano 2 & n. 4 & Janeiro-Junho 2014 & p. 159-183 \\
\hline
\end{tabular}


rays on the retina of the eye. In terms of the conceptual structure of natural science in those days the solution of the problem proposed by Helmholtz, his proposition that the work of the sense organs is necessarily supplemented by the work of the brain, which builds from sensory hints its hypotheses ("inferences") about objective reality, was the only possible one.

The point is that the objective images of the consciousness were thought of as mental phenomena depending on other phenomena for their external cause. In other words, analysis proceeded on the plane of dual abstraction, which was expressed, on the one hand, in the exclusion of the sensory processes from the system of the subject's activity and, on the other hand, in the exclusion of sensory images from the system of human consciousness. The idea of the object of scientific cognition as a system was not properly elaborated.

In contrast to this approach, which regards phenomena in isolation from one another, the systems analysis of consciousness demands that the "formative elements" of consciousness be studied in their internal relationships generated by the development of the forms of connection that the subject has with reality and, hence, primarily from the standpoint of the function that each of them fulfils in the processes of presenting a picture of the world to the subject. The sense-data incorporated in the system of consciousness do not reveal their function directly; subjectively this function is expressed only indirectly, in a non-differentiated "sense of reality". However, it immediately reveals itself as soon as there is any interference or distortion in the reception of external influences.

The profound nature of mental sensuous images lies in their objectivity, in the fact that they are generated in processes of activity forming the practical connection between the subject and the external objective world. No matter how complex these relations and the forms of activity that realise them become, the sensuous images retain their initial objective reference.

Of course, when we compare with the immense wealth of the cognitive results of developed human activity the contributions made to it directly by our sense perceptions, our sensibility, the first thing that strikes us is how limited they are, how almost negligible. What is more, we discover that sense perceptions constantly contradict our mental vision. This gives rise to the idea that sense perceptions only provide the push which sets our cognitive abilities in motion, and that the images of objects are generated by internal operations of thought, unconscious or conscious; in other words, that we

\begin{tabular}{|c|c|c|c|c|}
\hline Qenista Dialectus & Ano 2 & n. 4 & Janeiro-Junho 2014 & p. $159-183$ \\
\hline
\end{tabular}


should not perceive the objective world if we did not conceive it. But how could we conceive this world if it did not in the first place reveal itself to us in its sensuously given objectivity?

Sensuous images are a universal form of mental reflection generated by the objective activity of the subject. But in man sensuous images acquire a new quality, namely, their meaning or value. Values are thus the most important "formative elements" of human consciousness.

As we know, an injury to even the main sensory systems - sight and hearing does not destroy consciousness. Even deaf, dumb and blind children who have mastered the specifically human operations of objective activity and language (which can only be done by special training, of course) acquire a normal consciousness differing from the consciousness of people who can see and hear only in its sensuous texture, which is extremely poor. It is a different matter when for some reason or another this "hominisation" of activity and intercourse does not take place. In this case, despite the fact that the sensorimotor sphere may be entirely intact, consciousness does not arise.

Thus, meanings refract the world in man's consciousness. The vehicle of meaning is language, but language is not the demiurge of meaning. Concealed behind linguistic meanings (values) are socially evolved modes of action (operations), in the process of which people change and cognise objective reality. In other words, meanings are the linguistically transmuted and materialised ideal form of the existence of the objective world, its properties, connections and relations revealed by aggregate social practice. So meanings in themselves, that is to say, in abstraction from their functioning in individual consciousness, are just as "psychological" as the socially cognised reality that lies beyond them.

Meanings are studied - in linguistics, semiotics, and logic. At the same time, as one of the "formative elements" of the individual consciousness they are bound to enter the range of problems of philosophy. The chief difficulty of the philosophical problem of meaning lies in the fact that it reproduces all the contradictions involved in the wider problem of the correlation between the logical and the psychological in thinking, between the logic and psychology of concepts.

A solution to this problem offered by subjective-empirical psychology is that concepts (or verbal meanings) are a psychological product, the product of the association and generalisation of impressions in the consciousness of the individual subject, the results of which become attached to words. This point of view, as we know,

\begin{tabular}{|l|l|l|l|l|}
\hline Qevista Dialectus & Ano 2 & n. 4 & Janeiro-Junho 2014 & p. 159-183 \\
\hline
\end{tabular}


has found expression not only in psychology, but also in conceptions reducing logic to psychology.

Another alternative is to acknowledge that concepts and operations with concepts are controlled by objective logical laws, that psychology is concerned only with the deviations from these laws to be observed in primitive thinking, in conditions of pathology or great emotional stress, and that it is the task of psychology to study the ontogenetic development of concepts and thought. Indeed the study of this process predominates in the psychology of thought. Suffice it to mention the works of Piaget, Vygotsky and the numerous Soviet and foreign studies of the psychology of teaching.

Studies of how children form concepts and logical (mental) operations have made a major contribution in this field. It has been shown that the formation of concepts in the child's brain does not follow the pattern of the formation of sensuous generic images. Such concepts are the result of a process of assimilation of "ready-made", historically evolved meanings, and this process takes place in the child's activity during its intercourse with the people around it. In learning to perform certain actions, the child masters the corresponding operations, which are, in fact, in a compressed, idealised form, represented in meaning.

It stands to reason that initially the process of assimilating meanings occurs in the child's external activity with material objects and in the practical intercourse it involves. At the earliest stages the child assimilates certain specific, directly referable objective meanings; subsequently it also masters certain logical operations, but also in their external exteriorised form - otherwise they would not be communicable. As they are interiorised, they form abstract meanings or concepts, and their movement constitutes internal mental activity, activity "on the plane of consciousness".

Consciousness as a form of mental reflection, however, cannot be reduced to the functioning of externally assimilated meanings, which then unfold and control the subject's external and internal activity. Meanings and the operations enfolded in them do not in themselves, that is to say, in their abstraction from the internal relations of the system of activity and consciousness, form any part of the subject-matter of psychology. They do so only when they are considered within these relations, in the dynamics of their system.

This derives from the very nature of mental phenomena. As we have said, mental reflection occurs owing to the bifurcation of the subject's vital processes into the

\begin{tabular}{|l|l|l|l|l|}
\hline Qepista Dialectus & Ano 2 & n. 4 & Janeiro-Junho 2014 & p. 159-183 \\
\hline
\end{tabular}


processes that realise his direct biotic relations, and the "signal" processes that mediate them. The development of the internal relations generated by this division is expressed in the development of the structure of activity and, on this basis, also in the development of the forms of mental reflection. Subsequently, on the human level, these forms are so altered that, as they become established in language (or languages), they acquire a quasi-independent existence as objective ideal phenomena.

Moreover, they are constantly reproduced by the processes taking place in the heads of specific individuals, and it is this that constitutes the internal "mechanism" of their transmission from generation to generation and a condition of their enrichment by means of individual contributions.

At this point we reach the problem that is always a stumbling block in the analysis of consciousness. This is the problem of the specific nature of the functioning of knowledge, concepts, conceptual models, etc., in the system of social relations, in the social consciousness, on the one hand, and, on the other, in the individual's activity that realises his social relations, in the individual consciousness.

This problem inevitably confronts any analysis that recognises the limitations of the idea that meanings in the individual consciousness are only more or less complete projections of the "supra-individual" meanings existing in a given society. The problem is by no means removed by references to the fact that meanings are refracted by the specific features of the individual, his previous experience, the unique nature of his personal principles, temperament, and so on.

This problem arises from the real duality of the existence of meanings for the subject. This duality lies in the fact that meanings present themselves to the subject both in their independent existence - as objects of his consciousness - and at the same time as the means and "mechanism" of comprehension, that is, when functioning in processes that present objective reality to the subject. In this function meanings necessarily enter into internal relationships linking them with other "formative elements" of the individual consciousness; it is only in these internal systemic relationships that they acquire psychological characteristics,

Let us put this in a different way. When the products of socio-historical practice, idealised in meanings, become part of the mental reflection of the world by the individual subject, they acquire new systemic qualities. The major difficulty here is that meanings lead a double life. They are produced by society and have their history in the development of language, in the history of the development of forms of social

\begin{tabular}{|c|c|c|c|c|}
\hline Qenista Dialectus & Ano 2 & n. 4 & Janeiro-Junho 2014 & p. $159-183$ \\
\hline
\end{tabular}


consciousness; they express the movement of science and its means of cognition, and also the ideological notions of society - religious, philosophical and political. In this objective existence of theirs, meanings obey the socio-historical laws and at the same time the inner logic of their development.

However, despite all the inexhaustible wealth, all the diversity of this life of meanings (this is what all the sciences are about), there remains hidden within it another life and another kind of motion - their functioning in the processes of the activity and consciousness of specific individuals, even though they can exist only by means of these processes. In this second life of theirs meanings are individualised and "subjectivised" only in the sense that their movement in the system of social relations is not directly contained in them; they enter into another system of relationships, another movement. But the remarkable thing is that, in doing so, they do not lose their sociohistorical nature, their objectivity.

One aspect of the movement of meanings in the consciousness of specific individuals lies in their "return" to the sensuous objectivity of the world that was mentioned above. While in their abstractness, in their "supra-individuality", meanings are indifferent to the forms of sensuousness in which the world is revealed to the specific individual (it may be said that in themselves meanings are devoid of sensuousness), their functioning in the subject's realisation of actual relationships in life necessarily presupposes their reference to sensuous influences. Of course, the sensuousobjective reference that meanings have in the subject's consciousness need not necessarily be direct; it may be realised through all kinds of intricate chains of the mental operations, enfolded in them, particularly when these meanings reflect a reality that appears only in its remote, oblique forms. But in normal cases this reference always exists, and disappears only in the products of their movement, in their exteriorisations.

The other side of the movement of meanings in the system of the individual consciousness lies in their special subjectivity, which is expressed in the partiality, the bias which they acquire. This side is revealed, however, only by analysis of the internal relations that link meanings with yet another "formative element" of consciousness the personal meaning.

Let us consider this question a little more closely. Empirical psychology has been describing the subjectivity, the partiality of human consciousness for centuries. It has been observed in selective attention, in the emotional colouring of ideas, in the dependence of the cognitive processes on needs and inclinations. It was Leibniz in his

\begin{tabular}{|l|l|l|l|l|}
\hline Qepista Dialectus & Ano 2 & n. 4 & Janeiro-Junho 2014 & p. 159-183 \\
\hline
\end{tabular}


day who expressed this dependence in his well-known aphorism to the effect that "if geometry were as opposed to our passions and interests as is morality, we should contest its arguments and violate its principles despite all the proofs of Euclid and Archimedes ...,4

The difficulty lay in the psychological explanation of the partiality of cognition. The phenomena of consciousness appeared to have a dual determination - external and internal. They were accordingly interpreted as belonging to two different mental spheres, the sphere of the cognitive processes and the sphere of needs, of affection. The problem of correlating these two spheres, whether it was solved in the spirit of rationalistic conceptions or of deep-going psychological processes, was invariably interpreted from the anthropological standpoint, a standpoint that assumed the interaction of essentially heterogeneous factors or forces.

However, the true nature of the apparent duality of the phenomena of the individual consciousness lies not in their obedience to these independent factors, but in the specific features of the internal structure of human activity itself.

As we have already said, consciousness owes its origin to the identification in the course of labour of actions whose cognitive results are abstracted from the living whole of human activity and idealised in the form of linguistic meanings. As they are communicated they become part of the consciousness of individuals. This does not deprive them of their abstract qualities because they continue to imply the means, objective conditions and results of actions regardless of the subjective motivation of the people's activity in which they are formed. At the early stages, when people participating in collective labour still have common motives, meanings as phenomena of social consciousness and as phenomena of individual consciousness directly correspond to one another. But this relationship does not endure in further development. It disintegrates along with the disintegration of the original relationships between individuals and the material conditions and means of production, along with the emergence of the social division of labour and private property ${ }^{5}$. The result is that socially evolved meanings begin to live a kind of double life in the consciousness of individuals. Yet another relationship, another movement of meanings in the system of the individual consciousness is brought into being.

\footnotetext{
${ }^{4}$ G. W. Leibniz, Neue Abhandlungen über den menschlichen Verstand, Leipzig 1915.

${ }^{5}$ Karl Marx, A Contribution to the Critique of Political Economy, 1859.
}

\begin{tabular}{|l|l|l|l|l|}
\hline Qevista 2 ialectus & Ano 2 & n. 4 & Janeiro-Junho 2014 & p. 159-183 \\
\hline
\end{tabular}


This specific internal relationship manifests itself in the most simple psychological facts. For example, all older schoolchildren know the meaning of an examination mark and the consequences it will have. None the less, a mark may appear in the consciousness of each individual pupil in essentially different ways; it may, for example, appear as a step forward (or obstacle) on the path to his chosen profession, or as a means of asserting himself in the eyes of the people around him, or perhaps in some other way. This is what compels psychology to distinguish between the conscious objective meaning and its meaning for the subject, or what I prefer to call the "personal meaning". In other words, an examination mark may acquire different personal meanings in the consciousness of different pupils.

Although this interpretation of the relationship between the concepts of meaning and personal meaning has often been explained, it is still quite frequently misinterpreted. It would seem necessary therefore to return to the analysis of the concept of personal meaning once again. First of all, a few words about the objective conditions that lead to the differentiation of meanings and personal meanings in the individual consciousness. In his well-known article criticising Adolf Wagner, Marx observes that the objects of the external world known to man were originally designated as the means of satisfying his needs, that is to say they were for him "goods". "...They endow an object with the character of usefulness as though usefulness were intrinsic to the object itself," Marx writes ${ }^{6}$. This thought throws into relief a very important feature of consciousness at the early stages of development, namely the fact that objects are reflected in language and consciousness as part of a single whole along with the human needs which they concretise or "reify". This unity is, however, subsequently destroyed. The inevitability of its destruction is implied in the objective contradictions of commodity production, which generates a contradiction between concrete and abstract labour and leads to the alienation of human activity.

We shall not go into the specific features that distinguish the various socioeconomic formations in this respect. For the general theory of individual consciousness the main thing is that the activity of specific individuals is always "confined" (inséré) in the current forms of manifestation of these objective opposites (for example, concrete and abstract labour), which find their indirect, phenomenal expression in the individuals' consciousness, in its specific internal movement.

\footnotetext{
6 “Capital I," MECW, vol. 35, p. 46.
}

\begin{tabular}{|l|l|l|l|l|}
\hline Qevista 2 ialectus & Ano 2 & n. 4 & Janeiro-Junho 2014 & p. 159-183 \\
\hline
\end{tabular}


Historically, man's activity does not change its general structure, its "macrostructure". At every stage of historical development it is realised by conscious actions in which goals become objective products, and obeys the motives by which it was stimulated. What does change radically is the character of the relationships that connect the goals and motives of activity. These relationships are psychologically decisive. The point is that for the subject himself the comprehension and achievement of concrete goals, his mastering of certain modes and operations of action is a way of asserting, fulfilling his life, satisfying and developing his material and spiritual needs, which are reified and transformed in the motives of his activity. It makes no difference whether the subject is conscious or unconscious of his motives, whether they declare their existence in the form of interest, desire or passion. Their function, regarded from the standpoint of consciousness, is to "evaluate", as it were, the vital meaning for the subject of the objective circumstances and his actions in these circumstances, in other words, to endow them with personal meaning, which does not directly coincide with their understood objective meaning. Under certain conditions the discrepancy between personal meanings and objective meanings in individual consciousness may amount to alienation or even diametrical opposition.

In a society based on commodity production this alienation is bound to arise; moreover, it arises among people at both ends of the social scale. The hired worker, of course, is aware of the product he produces; in other words, he is aware of its objective meaning (Bedeutung) at least to the extent required for him to be able to perform his labour functions in a rational way. But this is not the same as the personal meaning (Sinn) of his labour, which lies in the wages for which he is working. "The twelve hours' labour, on the other hand, has no meaning for him as weaving, spinning, drilling, etc., but as earnings, which bring him to the table, to the public house, into bed." "7 This alienation also manifests itself at the opposite social pole. For the trader in minerals, Marx observes, minerals do not have thepersonal meaning of minerals.

The abolition of private property relations does away with this opposition between meaning and personal meaning in the consciousness of individuals; but the discrepancy between them remains.

The necessity of this discrepancy is implied in the deep-going prehistory of human consciousness, in the existence among animals of two types of sensibility that

\footnotetext{
${ }^{7}$ Marx, reference unknown.
}

\begin{tabular}{|l|l|l|l|l|}
\hline Qepista Dialectus & Ano 2 & n. 4 & Janeiro-Junho 2014 & p. 159-183 \\
\hline
\end{tabular}


mediate their behaviour in the objective environment. As we know, the perception of the animal is limited to the influences which have a signal-based connection with the satisfaction of its needs, even if such satisfaction is only eventual or possible ${ }^{8}$. But needs can perform the function of mental regulation only when they act as motivating objects (including the means of acquiring such objects or defending oneself from them). In other words, in the sensuality of animals the external properties of objects and their ability to satisfy certain needs are not separated from one another. As we know from Pavlov's famous experiment, a dog responds to the influence of the conditioning food stimulus by trying to reach it and lick it ${ }^{9}$. But the fact that the animal is unable to separate the perception of the object's external appearance from the needs it experiences does not by any means imply their complete coincidence. On the contrary, in the course of evolution their connections become increasingly mobile and extremely complex; only their separation from one another remains impossible. Such a separation takes place only at the human level, when verbal meanings drive a wedge between the internal connections of the two types of sensibility.

I have used the term drive a wedge (although perhaps it would have been better to say "intervene") only in order to accentuate the problem. In actual fact, in their objective existence, that is, as phenomena of social consciousness, meanings refract objects for the individual regardless of their relationship to his life, to his needs and motives. The straw which the drowning man clutches remains in his consciousness as a straw, regardless of the fact that this straw, if only as an illusion, acquires for him at that moment the personal meaning of a means of rescue.

At the early stages of the formation of consciousness objective meanings merge with personal meaning, but there is already an implicit discrepancy in this unity which inevitably assumes its own explicit form. It is this that makes it necessary to distinguish personal meaning in our analysis as yet another "formative element" of the system of individual consciousness. It is these personal meanings that create what L. Vygotsky has called the "hidden" plane of the consciousness, which is so often interpreted in psychology not as a formative element in the subject's activity, in the development of his motivation, but as something that is supposedly a direct expression of the intrinsic, essential forces originally implanted in human nature itself.

\footnotetext{
${ }^{8}$ This fact has given certain German writers grounds for making a distinction between environment (Umwelt), as that which is perceived by animals, and the world (Welt) which is perceived only by human consciousness.

${ }^{9}$ See I. P. Pavlov, Collected Works, Vol. 3, Book 1, Moscow 1951, p. 151.
}

\begin{tabular}{|l|l|l|l|l|}
\hline Qevista 2 ialectus & Ano 2 & n. 4 & Janeiro-Junho 2014 & p. 159-183 \\
\hline
\end{tabular}


In the individual consciousness the meanings assimilated from without separate, as it were, and at the same time unite the two types of sensibility: the sensuous impressions of the external reality in which the subject's activity proceeds, and the forms of sensuous experience of its motives, the satisfaction or non-satisfaction of the demands which lie behind them.

In contrast to objective meanings, personal meanings, like the sensuous tissue of the consciousness, have no "supra-individual", non-psychological existence. Whereas external sensuousness associates objective meanings with the reality of the objective world in the subject's consciousness, the personal meaning associates them with the reality of his own life in this world, with its motivations. It is the personal meaning that gives human consciousness its partiality.

We have already mentioned the fact that meanings are "psychologised" in the individual consciousness when they return to the sensuously given reality of the world. Another and, moreover, decisive factor which makes objective meanings into a psychological category is the fact that by functioning in the system of the individual consciousness they realise not themselves but the movement of personal meaning which embodies itself in them, the personal meaning which is the being-for-himself of the concrete subject.

Psychologically, that is to say, in the system of the subject's consciousness, and not as its subject-matter or product, meanings in general do not exist except insofar as they realise certain personal meanings, just as the subject's actions and operations do not exist except insofar as they realise some activity of the subject evoked by a motive, a need. The other side of the question lies in the fact that the personal meaning is always the meaning of something, a "pure", objectless meaning is just as meaningless as objectless existence.

The embodiment of personal meaning in objective meanings is a profoundly intimate, psychologically significant and by no means automatic or instantaneous process. This process is seen in all its fullness in works of literature and in the practice of moral and political education.

It is most clearly demonstrated in the conditions of class society, in the context of the ideological struggle. In this context personal meanings reflecting the motives engendered by a person's actual living relationships may fail to find objective meanings which fully express them, and they then begin to live in borrowed clothes, as it were. Picture the fundamental contradiction which this situation brings about. In contrast to

\begin{tabular}{|c|c|c|c|c|}
\hline Qenista Dialectus & Ano 2 & n. 4 & Janeiro-Junho 2014 & p. $159-183$ \\
\hline
\end{tabular}


society the individual has no special language of his own with meanings that he has evolved himself. His comprehension of reality can take place only by means of the "ready-made" meanings he assimilates from without - the knowledge, concepts, and views he receives through intercourse, in the various forms of individual and mass communication. This is what makes it possible to introduce into his consciousness or even impose upon that consciousness distorted or fantastic notions and ideas, including those that have no basis in his real, practical life experience. Because they have no proper basis they reveal their weakness in his consciousness, but at the same time, having become stereotypes, they acquire the capacity of any stereotype to resist, so that only the big confrontations of life can break them down. But even when they are broken down, the disintegrity of the consciousness, its inadequacy, is not removed; in itself the destruction of stereotypes causes only a devastation that may lead to psychological disaster. There must also be a transformation of the subjective personal meanings in the individual's consciousness into other objective meanings that adequately express them.

A closer analysis of this transformation of personal meanings into adequate (or more adequate) objective meanings shows that this occurs in the context of the struggle for people's consciousness that is waged in society. By this I mean that the individual does not simply "stand" in front of a display of meanings from which he has only to make his own choice, that these meanings - notions, concepts, ideas - do not passively await his choice but burst aggressively into his relations with the people who form the circle of his actual intercourse. If the individual is forced to choose in certain circumstances, the choice is not between meanings, but between the conflicting social positions expressed and comprehended through these meanings.

In the sphere of ideological notions this process is inevitable and universal only in class society. But in a way it continues to be active in any social system because the specific features of the individual's life, the specific features of his personal relations, intercourse and situations also survive, because his special features as a corporeal being and certain specific external conditions that cannot be identical for everyone remain unique.

There is no disappearance (nor could there be) of the constantly proliferating discrepancy between personal meanings which carry the intentionality, the partiality of the subject's consciousness, and the objective meanings, which though "indifferent" to them are the sole means by which personal meanings can be expressed. This is why the internal movement of the developed system of the individual's consciousness is full of

\begin{tabular}{|l|l|l|l|l|}
\hline Qepista 2 ialectus & Ano 2 & n. 4 & Janeiro-Junho 2014 & p. 159-183 \\
\hline
\end{tabular}


dramatic moments. These moments are created by personal meanings that cannot "express themselves" in adequate objective meanings, meanings that have been deprived of their basis in life and therefore, sometimes agonisingly, discredit themselves in the consciousness of the subject; such moments are also created by the existence of conflicting motives or goals.

It need not be repeated that this internal movement of the individual's consciousness is engendered by the movement of a person's objective activity, that behind the dramatic moments of the consciousness lie the dramatic moments of his real life, and that for this reason a scientific psychology of the consciousness is impossible without investigating the subject's activity, the forms of its immediate existence.

In conclusion I feel I must touch upon the problem of what is sometimes called the "psychology of life", the psychology of experience, which is once again being discussed in the literature. From what has been said in this article it follows that although a scientific psychology must never lose sight of man's inner world, the study of this inner world cannot be divorced from a study of his activity and does not constitute any special trend of scientific psychological investigation. What we call experiences are the phenomena that arise on the surface of the system of consciousness and constitute the form in which consciousness is immediately apparent to the subject. For this reason the experiences of interest or boredom, attraction or pangs of conscience, do not in themselves reveal their nature to the subject. Although they seem to be internal forces stimulating his activity, their real function is only to guide the subject towards their actual source, to indicate the personal meaning of the events taking place in his life, to compel him to stop for a moment, as it were, the flow of his activity and examine the essential values that have formed in his mind, in order to find himself in them or, perhaps, to revise them.

To sum up, man's consciousness, like his activity, is not additive. It is not a flat surface, nor even a capacity that can be filled with images and processes. Nor is it the connections of its separate elements. It is the internal movement of its "formative elements" geared to the general movement of the activity which effects the real life of the individual in society. Man's activity is the substance of his consciousness.

\begin{tabular}{|l|l|l|l|l|}
\hline Qevista Dialectus & Ano 2 & n. 4 & Janeiro-Junho 2014 & p. 159-183 \\
\hline
\end{tabular}

